\title{
Effect of Enzymatically Generated Reactive Oxygen Metabolites on the Cyclic Nucleotide Content in Isolated Rat Glomeruli
}

\section{Sudhir V. Shah}

With the technical assistance of Kathy Albe

Section of Nephrology, Department of Medicine, Tulane

Medical School and Veterans Administration Hospital,

New Orleans, Louisiana 70112

bstract. In the present study we examined the effect of reactive oxygen metabolites (generated by the xanthine-xanthine oxidase system), on adenosine- $3^{\prime}, 5^{\prime}$ cyclic monophosphate (cyclic AMP) and guanosine- $3^{\prime}, 5^{\prime}$ cyclic monophosphate (cyclic GMP) content in glomeruli and tubules that were isolated from rat renal cortex. Xanthine $(0.1 \mathrm{mM})$-xanthine oxidase $(0.025 \mathrm{U} / \mathrm{ml})$ significantly increased $(P<0.001)$ the cyclic AMP content in glomeruli from $18 \pm 1$ to $50 \pm 4 \mathrm{pmol} / \mathrm{mg}$ protein $(n=13)$. The response was dose dependent and was markedly inhibited $(\Delta \%-74 \pm 9, n=3)$ by allopurinol $\left(10^{-3}\right)$, a specific inhibitor of xanthine oxidase. Cyclic AMP content in the tubules, and the cyclic GMP content in glomeruli and tubules, were not altered by the xanthine-xanthine oxidase system. This lack of response was not due to lack of responsiveness of the tissues because parathyroid hormone caused a marked increase in the cyclic AMP content in tubules, and nitroprusside markedly increased the cyclic GMP content in glomeruli.

The increase in cyclic AMP in glomeruli was due to generation of reactive oxygen metabolites rather than of other products (e.g. uric acid) of the xanthine-xanthine oxidase reaction-addition of uric acid to incubations had no effect; using another substrate for xanthine oxidase, acetaldehyde significantly increased $(\Delta \% 112 \pm 7, n=4$,

This paper was presented in part at the National Meeting of the American Federation of Clinical Research in May 1983 (Clin. Res., 31:441A. [Abstr.] 1983).

Dr. Shah is the recipient of the Established Investigator Award from the American Heart Association with the funds contributed in part by the Louisiana Heart Association.

Received for publication 6 June 1983 and in revised form 30 March 1984.

J. Clin. Invest.

(c) The American Society for Clinical Investigation, Inc.

0021-9738/84/08/0393/09 \$1.00

Volume 74, August 1984, 393-401
$P<0.001)$ the cyclic AMP content; and catalase that destroys hydrogen peroxide caused a marked inhibition $(\Delta \%-90 \pm 5, n=4)$ of the response to xanthine-xanthine oxidase.

The marked inhibition by catalase, and the lack of effect of superoxide dismutase (in a concentration that completely scavenged superoxide) suggested hydrogen peroxide as the responsible oxygen metabolite for the observed effect. Glucose-glucose oxidase (a system that directly generates hydrogen peroxide), and direct addition of hydrogen peroxide caused a dose-dependent increase in the cyclic AMP content in glomeruli, which further supports the role of hydrogen peroxide as the responsible species for the observed effect. Additional experiments that used prostaglandin synthesis inhibitors and antagonists of serotonin and histamine suggested that hydrogen peroxide increases cyclic AMP content in glomeruli by enhancing prostaglandin synthesis.

\section{Introduction}

The role of adenosine $3^{\prime}, 5^{\prime}$-cyclic monophosphate (cyclic AMP) ${ }^{1}$ in regulating tubular function in the kidney is well established (1). Recently there has been increasing evidence for the importance of cyclic nucleotides in glomerular pathophysiology $(2,3)$. For example, it has been shown that infusion of dibutryl cyclic AMP or several hormones (3), all of which stimulate cyclic AMP production in the glomeruli (2), caused a fall in the glomerular ultrafiltration coefficient. In addition, recent studies have shown remarkable differences between the cyclic nucleotide systems in the glomeruli and tubules $(1,2)$, especially with respect to hormone responsiveness. The cyclic nucleotide content in the tubules is altered most strikingly by several extrarenal hormones (e.g. parathormone, vasopressin) that affect

1. Abbreviations used in this paper: cyclic AMP, adenosine-3',5'-cyclic monophosphate; cyclic GMP, guanosine-3',5'-cyclic monophosphate; HBSS, Hank's balanced salt solution; MIX, 1-methyl-3-isobutyl xanthine; PG, prostaglandins. 
tubular transport (1). In contrast, the cyclic nucleotide content in the glomeruli is altered most strikingly by several hormones that are locally produced in the kidney (4-6). Thus histamine $(2)$, serotonin $(2,7)$, and prostaglandins (PG) $(2,8)$ all caused a marked increase in cyclic AMP content in glomeruli. The fact that these local hormones are well-known mediators of inflammation and that several of their effects are mediated through cyclic nucleotides $(1,2,9,10)$ suggests an important role for cyclic nucleotides in modulating inflammatory responses in glomerular disease. This view is supported by extensive experimental evidence that cyclic AMP and guanosine $3^{\prime}, 5^{\prime}$-cyclic monophosphate (cyclic GMP) modulate inflammatory and immune responses, many of which are of particular relevance to renal pathophysiology $(1,2,9-11)$.

Recently, reactive oxygen metabolites which result from partial reduction of oxygen $(12,13)$ have been shown to be important mediators of the inflammatory response (14-16) and to cause cellular injury $(17,18)$. These reactive oxygen metabolites, including free radical species (e.g. superoxide and hydroxyl radicals) and other metabolites (e.g. hydrogen peroxide) have been shown to affect a variety of biological processes (14-16, 19-21) that are potentially important in renal disease. However, their effect on cyclic nucleotide content in intact cells and tissues has not been previously examined. In the present study we examined the effect of enzymatically generated reactive oxygen metabolites on cyclic AMP and cyclic GMP content in glomeruli and tubules isolated from rat renal cortex.

\section{Methods}

Isolation of glomeruli. Glomeruli were isolated by a combination of sieving and differential centrifugation as in our previous study (7) with only minor modifications. Sprague-Dawley rats that weighed 200-250 $\mathrm{g}$ were anesthetized with pentobarbital $(50 \mathrm{mg} / \mathrm{kg})$ and a polyethylene catheter (PE 100) was inserted into the lower abdominal aorta immediately above the bifurcation. Subsequently, the aorta was clamped above the renal arteries, the renal veins were cut, and the kidneys were perfused with ice-cold Hank's balanced salt solution (HBSS). After the kidneys were blanched, they were removed and decapsulated. Kidneys that did not blanch well were discarded. All subsequent preparative steps were carried out at $4^{\circ} \mathrm{C}$. The cortex was carefully dissected, minced with a blade, and gently squeezed through a stainless steel sieve (250- $\mu \mathrm{M}$ opening) using a metal spatula. The resulting suspension of cortical tissue was washed four times in the buffer by repeated centrifugation at 200 $g$ for 2 min to eliminate small fragments in the supernatant. The resultant pellet was resuspended in buffer and passed sequentially through each of the Nitex nylon sieves (Tetko Inc., Elmsford, NY) of 390-, 250-, and $213-\mu \mathrm{M}$ pore openings. The particles retained on the $390-$ and $250-\mu \mathrm{M}$ sieve consisted of tubular fragments and were collected as a tubular fraction. This tubular fraction, referred to later in the text as "tubules", was washed again on the $250-\mu \mathrm{M}$ nylon screen with HBSS to reduce glomerular contamination to a negligible level. To obtain glomeruli, the suspension resulting after filtering through $213-\mu \mathrm{M}$ sieve was passed through a screen cloth (Nitex No. $25, \sim 60-\mu \mathrm{M}$ pore opening); this step allowed debris and small fragments to pass through, with glomeruli retained on the cloth. The retained glomeruli were recovered by gently rinsing with buffer. Both glomerular and tubular preparations were transferred to preweighed polyallomer tubes, and were centrifuged at
$1,500 \mathrm{~g}$ for $5 \mathrm{~min}$; the supernatant was removed by aspiration, and the tubes were weighed again to determine approximate wet weight of the preparations. Glomeruli or tubules were suspended in fresh HBSS so that $\sim 4-6 \mathrm{mg}$ (wet weight) of glomeruli and 8-10 mg of tubules were contained in $100 \mu$ l of HBSS suspension. Glomeruli that were prepared in this way were preserved well and without capsules. The purity of each preparation was evaluated by counting glomeruli under light microscopy; only preparations with $>90 \%$ purity were used. It must be emphasized that whereas the glomerular preparation was relatively homogenous, the tubular fraction consisted of diverse tubular segments from the renal cortex.

Incubations and assays. Incubations of tissue preparation and analyses of cyclic nucleotides were conducted with only minor modifications to the method used in our previous studies (7). Freshly prepared glomeruli (4-6 mg, wet weight) and tubules (8-12 mg, wet weight) were distributed randomly (in duplicate or triplicate for each experimental condition) into 10-ml glass homogenizer tubes (size A, Thomas Scientific Products, Philadelphia, PA), kept in crushed ice at $0^{\circ} \mathrm{C}$, and aliquots for protein determination were taken. Xanthine (final concentration $0.1 \mathrm{mM}$ ) and in some experiments superoxide dismutase, catalase (heat inactivated in control tubes), ibuprofen, meclofenamate, metiamide, or methysergide were added before preincubation at $37^{\circ} \mathrm{C}$ for $20 \mathrm{~min}$ in a Dubnoff shaking water bath. At the end of the 20-min preincubation period, 1-methyl-3-isobutyl xanthine (MIX) dissolved in HBSS was added to all tubes. At the same time, enzymes, and/or drugs, or hormones were added to the experimental tubes; the control tubes received buffer in equal volume. These additions were made within an interval of $6 \mathrm{~s}$. The final volume of each suspension was then $500 \mu \mathrm{l}$, with $0.5 \mathrm{mM}$ MIX, and the final concentration of various test agents were as indicated in Results. After the various test agents and MIX were added, the tubes were incubated for an additional $2 \mathrm{~min}$ at $37^{\circ} \mathrm{C}$ in a metabolic shaking water bath. The incubation was terminated by adding $500 \mu \mathrm{l}$ of icecold $10 \%$ trichloroacetic acid and homogenizing immediately with a Teflon pestle (10 strokes). After adding tracer amounts of tritiated cyclic AMP, and in some experiments, tritiated cyclic GMP to aliquots for monitoring recovery, the precipitated proteins were removed by centrifugation. Trichloroacetic acid was removed from the supernatant by repeated extraction $(\times 4)$ with ethyl ether; the remaining ether was heat evaporated, and the samples were used for determinations of cyclic nucleotides by the radioimmunoassay (RIA) and for measurements of recovery. Samples from each experiment were processed (extraction, RIA, and protein determination) at the same time, using the same batch of reagents.

Extracts were not routinely passed through Dowex-1 columns before cyclic AMP and cyclic GMP determinations by RIA because of the small quantity of material; in our previous study we obtained similar results with or without Dowex-1 formate column separation (7). The RIA for cyclic AMP and cyclic GMP was carried out in triplicate in acetylated samples, exactly as described in the New England Nuclear (Boston, MA) RIA kits. The radioactivity of the samples was counted in a Beckman gamma counter, model 8000 (Beckman Instruments Inc., Fullerton, CA).

The quantity of tritiated cyclic AMP and tritiated cyclic GMP tracers for recovery measurements (liquid scintillation counter, model 9000 , Beckman Instruments Inc.) which contributed to the final concentration of cyclic nucleotides was calculated and subtracted from each sample. After correction for recovery and after subtraction of the added radioactive tracer, the contents of cyclic AMP and cyclic GMP in samples were expressed as picomoles per milligram of protein. The values from the duplicate or triplicate incubation tubes for each condition were averaged 
to obtain a single value. An exception was in the results depicted in dose-response curves where each value is based on determination in a single incubation tube. The protein content was determined by the method of Lowry et al. (22) in aliquots of glomeruli and tubules from each incubation tube. Thus, the protein content was determined in the same tissues as that used for measurements of cyclic nucleotide content. Because glomeruli and tubules were homogenized together with the incubation medium, the content of cyclic AMP and cyclic GMP represented a sum of the cyclic nucleotides contained within cells and in the incubation medium. The content of cyclic nucleotide was expressed in picomoles per milligram of protein in the incubation mixture.

Because the effect of xanthine-xanthine oxidase on cyclic AMP has not been previously described, we carried out the following experiments to document the validity of the cyclic AMP measurements (data not shown). (a) When tissue extracts from glomeruli that had been incubated with xanthine-xanthine oxidase were treated with phosphodiesterase, no cyclic AMP was detected. (b) Serial dilutions of the tissue extracts showed linearity, and when each tube was spiked with a constant amount of cyclic AMP standard, the resultant curve was linear and parallel to the original unspiked extract dilution curve (23). (c) Addition of extracts that were obtained by incubating xanthine-xanthine oxidase without glomeruli to several cyclic AMP standards, gave similar values, which indicated that the products of xanthine-xanthine oxidase did not affect antigen-antibody binding in the cyclic AMP RIA. (d) Finally, the values of cyclic AMP obtained by incubation of glomeruli with xanthine-xanthine oxidase were a linear function of the glomerular protein (data not shown). Taken together, these observations confirmed the validity of the cyclic AMP measurements.

Superoxide dismutase inhibitable reduction of ferricytochrome $c$ $(0.3 \mathrm{mM})(24)$ was used to measure the superoxide that was produced by incubating $0.1 \mathrm{mM}$ xanthine with varying concentrations of xanthine oxidase. These incubations were carried out at ambient temperature in a double-beam spectrophotometer with reference cuvette that contained an excess of superoxide dismutase $(200 \mu \mathrm{g} / \mathrm{ml})$ in addition to the complete reaction mixture. The change in absorbance at $550 \mathrm{nM}$ was recorded, and from the linear portion of the curve the rate of superoxide production was calculated using an extinction coefficient of $21.1 \mathrm{mM}^{-1} \mathrm{~cm}^{-1}$. The xanthine oxidase activity was measured by recording the increase in absorbance at $290 \mathrm{nM}$ and using the extinction coefficient of $1.22 \times 10^{-4} \mathrm{M}^{-1} \mathrm{~cm}^{-1}$ uric acid (25). The hydrogen peroxide produced by glucose-glucose oxidase reaction was measured spectrophotometrically by the peroxidase-catalyzed oxidation of $O$-dianisidene (26); $1 \mathrm{U}$ of glucose oxidase was defined as the amount of enzyme required to generate $1 \mu \mathrm{mol}$ of hydrogen peroxide per minute.

Materials. Xanthine, xanthine oxidase (grade I), glucose oxidase (type V), thymol-free bovine catalase $(17,000 \mathrm{U} / \mathrm{mg})$, bovine heart phosphodiesterase, allopurinol, serotonin (5-hydroxytryptamine creatinine sulfate), and uric acid were all obtained from Sigma Chemical Co., St. Louis, MO. Bovine superoxide dismutase $(3,000 \mathrm{U} / \mathrm{mg}$ protein) was obtained from Diagnostic Data, Inc., Mountain View, CA. Synthetic 1, 34- $N$-terminal tetratriacontapeptide of parathyroid hormone $(6,000 \mathrm{U} /$ $\mathrm{mg}$ ) was purchased from Beckman Instruments Inc., Bioproducts, Spinco Div., Palo Alto, CA, and MIX from Aldrich Chemical Co., Inc., Milwaukee, WI. Methysergide maleate was a gift from Sandoz Pharmaceuticals, Hanover, NJ; metaimide was a gift from Dr. Mendelson, Smith, Kline \& French Co., Philadelphia, PA; meclofenamate was from ParkeDavis, Div. of Warner-Lambert Co., Morris Plains, NJ, and ibuprofen (sodium ibuprofenate $0.09 \% \mathrm{w} / \mathrm{o}$ benzyl alcohol) was from Upjohn, Kalamazoo, MI. Acetaldehyde and hydrogen peroxide were purchased from J. T. Baker Chemical Co., Phillipsburg, NJ, and HBSS (450-1201) was from Grand Island Biological Company, Grand Island, NY. Tritated cyclic AMP, tritiated cyclic GMP, and the RIA kits for cyclic AMP and cyclic GMP were obtained from New England Nuclear, and the nylon screens for sieving were from Tetko Inc.

\section{Results}

In the present study we utilized xanthine-xanthine oxidase as a source for the reactive oxygen metabolites. This system has previously been shown to produce superoxide anion, hydrogen peroxide, and hydroxyl radicals $(24,27)$. In our initial experiments, we measured the amount of superoxide anion that was generated (superoxide dismutase inhibitable reduction of ferricytochrome $c$ ) with $0.1 \mathrm{mM}$ xanthine and with various concentrations of xanthine oxidase. Using xanthine oxidase over a range of $0.01-0.08 \mathrm{U} / \mathrm{ml}, \sim 8-40 \mathrm{nmol} / \mathrm{min}$ of superoxide were generated. Utilizing xanthine oxidase over the similar range of concentrations, we examined the effect on cyclic AMP and cyclic GMP content in glomeruli and tubules isolated from rat cortex. As in our previous studies $(2,7)$, these incubations were carried out in the presence of MIX, an inhibitor of cyclic AMP, and cyclic GMP phosphodiesterase, in order to optimize conditions for detecting increases in cyclic nucleotides. Xanthine oxidase in concentration of $0.005 \mathrm{U} / \mathrm{ml}$ caused a significant increase in cyclic AMP content; higher concentrations increased cyclic AMP content, with the maximum response being observed with 0.05 $\mathrm{U} / \mathrm{ml}$ (Fig. 1). In contrast to the effect on glomeruli, no effect on cyclic AMP content in tubules was observed (Table I). In the same experiments, parathyroid hormone $(10 \mu \mathrm{g} / \mathrm{ml})$ caused a marked increase in cyclic AMP in tubules (control: 9.1 1.0 ; PTH: $31.4 \pm 5.1 \mathrm{pmol} / \mathrm{mg}$ protein; $n=4$ ). Xanthine-xanthine oxidase also had no effect on cyclic GMP content in either glomeruli or tubules (Table I). Although the data with one concentration of xanthine oxidase $(0.025 \mathrm{U} / \mathrm{ml})$ are shown in the

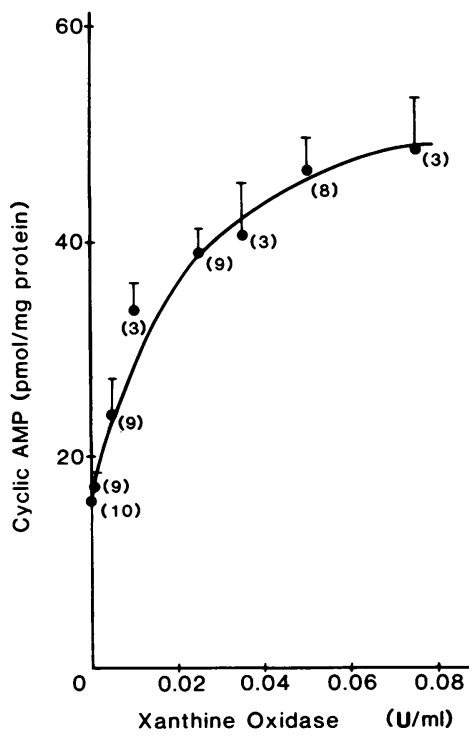

Figure 1. Effect of xanthine $(0.1 \mathrm{mM})$ and increasing concentrations of xanthine oxidase on cyclic AMP content in glomeruli. Incubations were carried out in presence of $5 \times 10^{-4} \mathrm{M}$ MIX. Values are mean \pm SEM. Additional experimental detail is described under Methods. 
Table I. Effect of Xanthine-Xanthine Oxidase on Cyclic Nucleotides in Glomeruli and Tubules*

\begin{tabular}{|c|c|c|c|c|}
\hline \multirow[b]{2}{*}{ Addition $\ddagger$} & \multicolumn{2}{|l|}{ Cyclic AMP } & \multicolumn{2}{|l|}{ Cyclic GMP } \\
\hline & Glomeruli & Tubules & Glomeruli & Tubules \\
\hline & $\begin{array}{l}\text { pmol/mg } \\
\text { protein }\end{array}$ & $\begin{array}{l}\mathrm{pmol} / \mathrm{mg} \\
\text { protein }\end{array}$ & $\begin{array}{l}\text { pmol/mg } \\
\text { protein }\end{array}$ & $\begin{array}{l}\mathrm{pmol} / \mathrm{mg} \\
\text { protein }\end{array}$ \\
\hline None & $17.1 \pm 1.8(5)$ & $8.4 \pm 1.1(5)$ & $1.8 \pm 0.4(5)$ & $0.7 \pm 0.2(5)$ \\
\hline oxidase & $38.7 \pm 4.1(5) \S$ & $7.0 \pm 0.6(5)$ & $1.8 \pm 0.3(5)$ & $0.4 \pm 0.2(5)$ \\
\hline
\end{tabular}

* Incubation conditions described in detail under methods. Values shown are mean $\pm S E M$. The numbers in parentheses indicate the number of experiments. $¥$ All incubations were carried out in the presence of a phosphodiesterase inhibitor, MIX $\left(5 \times 10^{-4} \mathrm{M}\right)$. Final concentrations of xanthine and xanthine oxidase were $0.1 \mathrm{mM}$ and $0.025 \mathrm{U} / \mathrm{ml}$, respectively.

$\S P<0.01$, compared with control values obtained without addition of xanthine-xanthine oxidase. Paired $t$ test.

table, no increase in cyclic GMP was observed over the same range of concentrations as that shown in Fig. 1. In the same experiments, nitroprusside $\left(10^{-3} \mathrm{M}\right)$, as in our previous studies, $(2,7)$ caused a marked increase in cyclic GMP content in glomeruli (control: $3.0 \pm 0.8$; nitroprusside: $71.1 \pm 21.1 \mathrm{pmol} / \mathrm{mg}$ protein; $n=3$ ).

As mentioned above, the incubations were carried out in presence of MIX to optimize the conditions for detecting increases in cyclic nucleotides. In a few experiments we examined the effect of xanthine-xanthine oxidase in the absence of MIX. As expected, the basal (unstimulated) values of cyclic AMP were much lower (Table II) than in the presence of MIX. Addition of xanthine-xanthine oxidase increased the cyclic AMP content in glomeruli from $4.2 \pm 0.6$ to $7.9 \pm 0.9 \mathrm{pmol} / \mathrm{mg}$ protein $(n=5), P<0.01$ representing a $\Delta \%$ increase of $96 \pm 20(P$ $<0.01)$. Thus, even in the absence of phosphodiesterase inhib-

Table II. Effect of Xanthine-Xanthine Oxidase on Cyclic AMP Content in the Absence of a Phosphodiesterase Inhibitor

\begin{tabular}{lccc}
\hline Experiment & Control & $\begin{array}{l}\text { Xanthine- } \\
\text { xanthine oxidase }\end{array}$ & Change* \\
\hline & Cyclic $A M P$, pmol/mg protein & $\%$ \\
1 & 3.7 & 10.0 & 170 \\
2 & 6.4 & 9.5 & 48 \\
3 & 4.0 & 7.9 & 98 \\
4 & 3.7 & 7.0 & 92 \\
5 & 2.9 & 5.0 & 71 \\
Mean & 4.2 & $7.9 \ddagger$ & $96 \ddagger$ \\
SEM & \pm 0.6 & \pm 0.9 & \pm 20
\end{tabular}

* $\Delta \%$ change equals (Experiment value - control value)/(control value) $\times 100$.

$\ddagger P<0.01$, compared with control using paired $t$ test. itor, the effect of xanthine-xanthine oxidase on the cyclic AMP content in glomeruli could be demonstrated. No effect on cyclic GMP content of glomeruli was observed in the absence of MIX (control: $0.7 \pm 0.06$; xanthine oxidase: $0.8 \pm 0.05 \mathrm{pmol} / \mathrm{mg}$ protein; $n=3)$. In additional experiments, we examined the time course of the changes in cyclic AMP in glomeruli. As shown in Fig. 2, an increase in cyclic AMP was first noted at $30 \mathrm{~s}$, the earliest time point examined, and reached a peak at $5 \mathrm{~min}$, and declined thereafter. In subsequent experiments, the standard incubation included xanthine $(0.1 \mathrm{mM})$, xanthine oxidase $(0.025 \mathrm{U} / \mathrm{ml})$, MIX $(0.5 \mathrm{mM})$, and the incubation time of $2 \mathrm{~min}$.

We examined the requirement of a complete reactive oxygengenerating system for the observed effect on cyclic AMP. Xanthine or xanthine oxidase by itself had no effect on cyclic AMP content in glomeruli, whereas a marked increase was noted when both xanthine and xanthine oxidase were included in the incubations (Table III). Because xanthine oxidase is often contaminated with proteases, the lack of direct effect of xanthine oxidase by itself indicates that the observed effects were due to xanthine oxidase acting on xanthine as a substrate rather than being due to some direct effect of contaminating proteases (28, 29). This was further confirmed by utilizing allopurinol, which is a specific inhibitor of xanthine oxidase (30). In control vials, addition of xanthine-xanthine oxidase increased the glomerular cyclic AMP content to $37.7 \pm 2.9(n=3)$, an increase of $21.4 \pm 0.7$ $\mathrm{pmol} / \mathrm{mg}$ protein (Fig. 3) over the basal values (16.3 $\pm 2.9 \mathrm{pmol} /$ $\mathrm{mg}$ protein). In contrast, in the presence of allopurinol $\left(10^{-3}\right.$ $M)$, addition of xanthine-xanthine oxidase resulted in the total cyclic AMP content of $18.1 \pm 2.4(P<0.05$, compared with values without allopurinol), which was an increase of 5.6 \pm 2.2 $\mathrm{pmol} / \mathrm{mg}$ protein $(P<0.05)$ over the basal value $(12.5 \pm 1.2$ $\mathrm{pmol} / \mathrm{mg}$ protein). Thus, allopurinol caused a $74 \pm 9 \%(P<0.05)$ inhibition of the respose to xanthine-xanthine oxidase (Fig. 3) without having a significant effect on the basal values of cyclic AMP. Similarly, allopurinol $\left(10^{-4} \mathrm{M}\right)$ caused a significant although smaller degree of inhibition of the cyclic AMP response to xanthine-xanthine oxidase (Fig. 3) while having no significant effect on the basal values (without allopurinol, 15.8 \pm 2.1 ; with allopurinol, $12.4 \pm 1.7 \mathrm{pmol} / \mathrm{mg}$ protein, $n=3$ ).

To examine the possibility that the increase in cyclic AMP

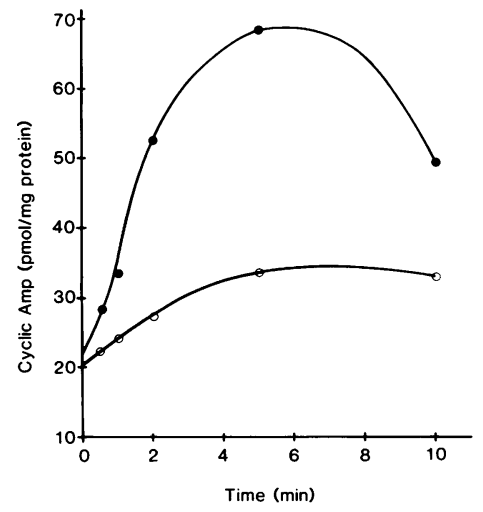

Figure 2. Time course of the effect of xanthine $(0.1$ $\mathrm{mM}$ )-xanthine oxidase $(0.025 \mathrm{U} / \mathrm{ml})$ on cyclic AMP content in glomeruli. Glomeruli were incubated with (closed circles) or without (open circles) xanthine-xanthine oxidase for various times as shown in the figure. Each point represents the mean of three samples. 
Table III. Effect of Xanthine-Xanthine Oxidase on Cyclic AMP Content in Glomeruli

\begin{tabular}{ll}
\hline Addition* $^{*}$ & Cyclic AMP \\
\hline & $\mathrm{pmol} / \mathrm{mg} \mathrm{protein}$
\end{tabular}

None

Xanthine (0.1 mM)

Xanthine oxidase $(0.025 \mathrm{U} / \mathrm{ml})$

Xanthine + heat-inactivated xanthine oxidase

Xanthine + xanthine oxidase

$17.9 \pm 1.4(13)$

$14.6 \pm 0.9(3)$

$21.8 \pm 4.5(3)$

$19.0 \pm 3.7(3)$

$49.6 \pm 4.1(13) \ddagger$

* All incubation carried out in presence of MIX $\left(5 \times 10^{-4} \mathrm{M}\right)$. Values are mean $\pm S E M$. Number of experiments in parentheses.

$\ddagger P<0.001$, compared with values obtained without addition of xanthine-xanthine oxidase. Paired $t$ test.

content was due to some other products of xanthine-xanthine oxidase reaction rather than to reactive oxygen metabolites, we utilized another substrate for xanthine oxidase. With acetaldehyde as a substrate for xanthine oxidase, we observed a $112 \pm 7 \%(n=4, P<0.001)$ increase in the cyclic AMP content in glomeruli (Table IV). In addition, substituting uric acid for xanthine-xanthine oxidase in the incubations had no effect on the cyclic AMP content in the glomeruli (data not shown).

To further substantiate that the observed effects were due to production of reactive oxygen metabolites by xanthine-xanthine oxidase and to delineate the oxygen metabolite responsible for the increase in the glomerular cyclic AMP content, we ex-

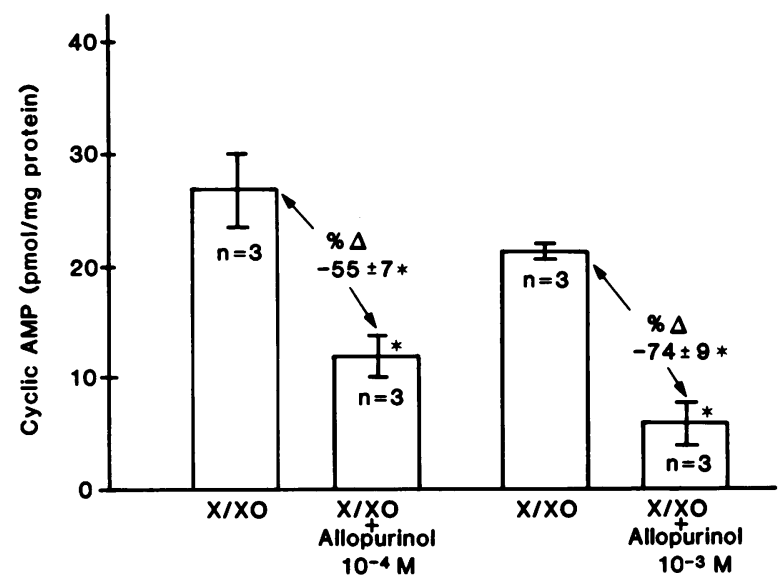

Figure 3. Effect of allopurinol on the xanthine-xanthine oxidase-induced increase in the cyclic AMP content in glomeruli. The basal value (without xanthine-xanthine oxidase) was subtracted to obtain the response to xanthine-xanthine oxidase in the presence of allopurinol (experimental value) and in the absence of allopurinol (control value). Allopurinol $10^{-3}$ or $10^{-4} \mathrm{M}$ had no significant effect on the basal values (see text). $\Delta \%$ change was calculated as follows: $\Delta \%$ equals (experimental value-control value)/(control value) $\times 100$. $^{*}$, $P<0.05$, paired $t$ test.
Table IV. Effect of Acetaldehyde-Xanthine Oxidase on Cyclic AMP Content in Glomeruli*

\begin{tabular}{llcc}
\hline Experiment & Acetaldehyde & $\begin{array}{l}\text { Acetaldehyde } \\
+ \text { xanthine oxidase }\end{array}$ & Increase \\
\hline & \multicolumn{1}{c}{ Cyclic AMP, pmol/mg protein } & $\%$ \\
1 & 21.7 & 43.2 & 99 \\
2 & 11.7 & 26.5 & 126 \\
3 & 9.8 & 21.9 & 123 \\
4 & $\underline{11.9}$ & $\underline{23.8}$ & $\underline{99}$ \\
Mean & 13.8 & $28.8 \ddagger$ & $112 \S$ \\
SEM & \pm 2.7 & \pm 4.9 & \pm 7 \\
\hline
\end{tabular}

* Incubation conditions as described in methods. Acetaldehyde 5 $\mathrm{mM}$, xanthine oxidase $0.025 \mathrm{U} / \mathrm{ml}$.

$\ddagger P<0.01$, paired $t$ test.

$\S P<0.001$, paired $t$ test.

amined the effect of superoxide dismutase and catalase. Superoxide dismutase $(200 \mu \mathrm{g} / \mathrm{ml})$, a scavenger of superoxide anion, had no significant effect $(\Delta \% 5 \pm 18, n=4)$ on the xanthinexanthine oxidase-induced increase in the cyclic AMP content in glomeruli. It must be emphasized that in separate experiments using the ferricytochrome $c$ assay, we confirmed that the 200 $\mu \mathrm{g} / \mathrm{ml}$ superoxide dismutase completely scavenged the superoxide anion that was produced by the xanthine-xanthine oxidase reaction. In contrast, catalase $(200 \mu \mathrm{g} / \mathrm{ml})$, which destroys hydrogen peroxide, caused a marked inhibition $(\Delta \%-90 \pm 5$, $n=4, P<0.001$ ) of the cyclic AMP accumulation in response to xanthine-xanthine oxidase. As shown in Fig. 4, the inhibitory effect of catalase was dose dependent.

These results suggested that hydrogen peroxide is the oxygen species responsible for the observed effects with xanthine-xanthine oxidase. Therefore, we examined the effect of glucoseglucose oxidase on the cyclic AMP content in glomeruli. This

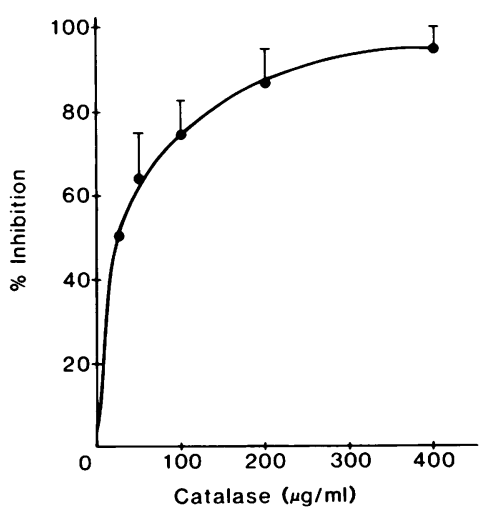

Figure 4. Effect of catalase on the xanthine-xanthine oxidase-induced increase in cyclic AMP content in glomeruli. For details, see Methods and legend to Table I. Each value represents the mean \pm SEM of three separate experiments (except $25 \mu \mathrm{g} / \mathrm{ml}$, only one experiment), and each experiment was carried out in triplicate. The basal values (without xanthine-xanthine oxidase) were subtracted to obtain the response to xanthine-xanthine oxidase in the presence of the active enzyme (experimental value) and in the presence of heatinactivated enzyme (control value). $\Delta \%$ change was calculated as described in the legend to Fig. 3. 
system, which directly produces hydrogen peroxide (31) without superoxide as an intermediate, increased the cyclic AMP content in glomeruli in a dose-dependent manner, the response being first noted with $0.01 \mathrm{U} / \mathrm{ml}$ and the maximum response being observed with $0.25 \mathrm{U} / \mathrm{ml}$ of glucose oxidase (Fig. 5). Catalase $(400 \mu \mathrm{g} / \mathrm{ml})$ completely inhibited the response to glucose-glucose oxidase (data not shown), which confirmed the role of hydrogen peroxide in increasing the cyclic AMP content in glomeruli. Finally, addition of exogenous hydrogen peroxide to incubations caused a dose-dependent increase in the cyclic AMP content in glomeruli, with significant effect being first observed with 5 $\mathrm{nmol} / \mathrm{ml}$ of hydrogen peroxide (Fig. 6). In the same experiments using the same concentrations of hydrogen peroxide, no effect on cyclic AMP content in tubules or cyclic GMP content in glomeruli and tubules was observed (data not shown).

In the present study, we also carried out studies utilizing PG synthesis inhibitors (ibuprofen and meclofenamate), histamine antagonist (metiamide), and serotonin antagonist (methysergide) as an initial approach to understanding the mechanisms by which reactive oxygen metabolites increase the cyclic AMP content in glomeruli. Metiamide $\left(10^{-4}\right)$ had no significant effect either on the basal value or the response to xanthine-xanthine oxidase (Table V). In the same concentration, metiamide caused a marked inhibition of the response to histamine. Similarly, methysergide $\left(10^{-4}\right)$ had no significant effect on either the basal values or the response of the glomeruli to xanthine-xanthine oxidase. We confirmed that the same concentrations of methysergide markedly inhibited the response to serotonin $\left(10^{-4}\right)$. (Serotonin: $169 \pm 16.5$; serotonin plus methysergide: $47.7 \pm 0.19 \mathrm{pmol} / \mathrm{mg}$ protein, $n=3$ ). In contrast, ibuprofen and meclofenamate, in concentrations that have been

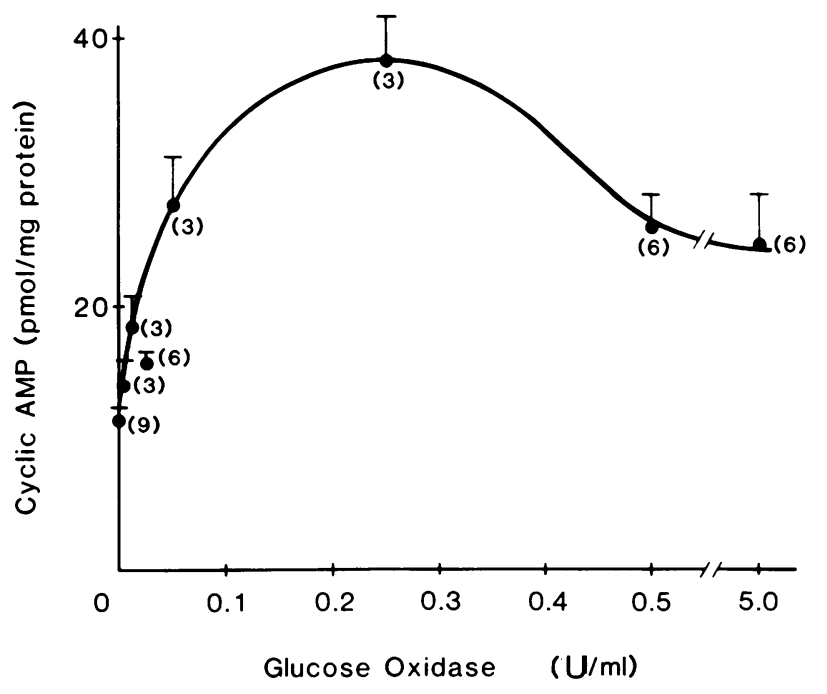

Figure 5. Effect of glucose-glucose oxidase on cyclic AMP content in glomeruli. Incubation conditions are the same as in experiments depicted in Fig. 2. Each point represents the mean \pm SEM.

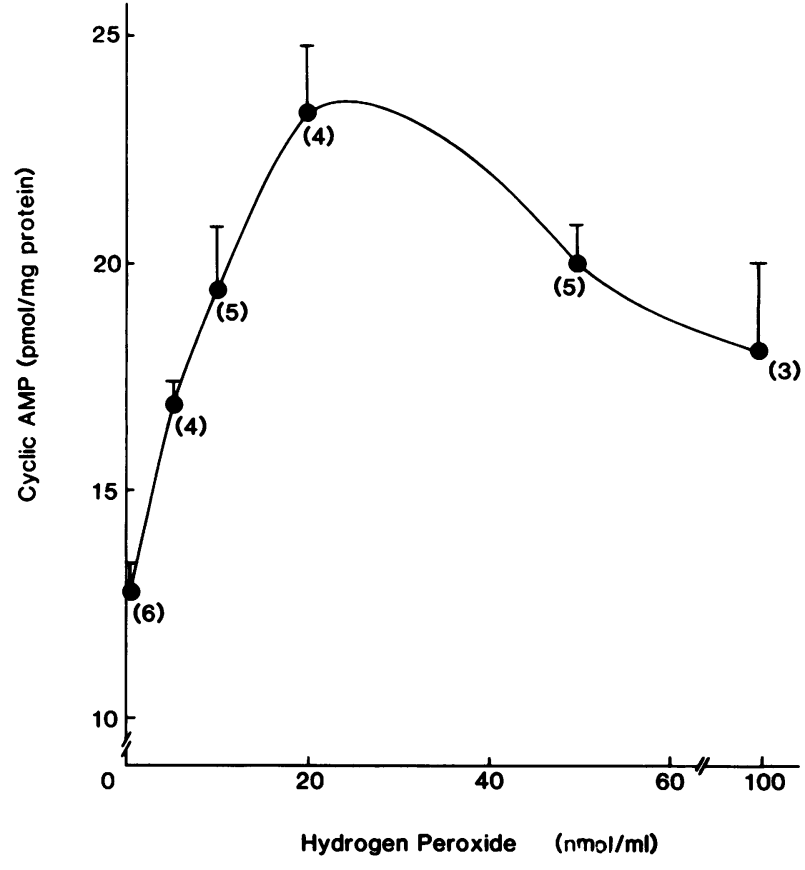

Figure 6. Effect of direct addition of hydrogen peroxide on the cyclic AMP content in glomeruli. Incubation conditions are the same as in experiments depicted in Fig. 1. Each point represents the mean \pm SEM.

shown to inhibit PG synthesis $(5,32)$, significantly inhibited the response to xanthine-xanthine oxidase (Table V). This was not a nonspecific inhibition of the response because neither ibuprofen nor meclofenamate inhibited the response to histamine (Table V). Also, the values of cyclic AMP that were obtained by addition of $3.10^{-5} \mathrm{PGE}_{2}(8)$ to incubation with xanthine-xanthine oxidase and PG synthesis inhibitors, were similar to values obtained by addition of $\mathrm{PGE}_{2}$ alone (Table $\mathrm{V}$ ). Taken together, these data suggest that the ability of reactive oxygen metabolites to increase cyclic AMP content in glomeruli is due to enhanced PG synthesis.

\section{Discussion}

Our data show that the xanthine-xanthine oxidase system increases cyclic AMP content in glomeruli but has no effect on cyclic GMP content. It must be noted, however, that in broken cell preparations, the role of hydrogen peroxide and free radical mechanisms in the activation of guanate cyclase has been suggested $(33,34)$.

Because proteases have been shown to increase cyclic AMP content in other tissues $(28,29)$ it was important to be certain that observed effect on cyclic AMP content in glomeruli was not due to proteases that are often present in the xanthine oxidase preparation. The lack of effect on xanthine oxidase by itself, along with the marked inhibition $(\Delta \% 74 \pm 9)$ of the re- 
Table V. Effect of PG Synthesis Inhibitors, Histamine, and Serotonin Antagonists on Xanthine-Xanthine Oxidase-induced Increase in Cyclic AMP in Glomeruli*

\begin{tabular}{|c|c|c|c|c|c|}
\hline & \multicolumn{3}{|l|}{ Cyclic AMP pmol/mg protein } & & \\
\hline & \multicolumn{5}{|l|}{ Xanthine-xanthine oxidase $\ddagger$} \\
\hline & Addition\$ & - & + & $\Delta$ & \% Inhibition \\
\hline \multirow[t]{5}{*}{ A } & None & $15.8 \pm 3.0$ & $38.1 \pm 0.9$ & $22.3 \pm 3.6$ & \\
\hline & Ibuprofen $\left(10^{-4} \mathrm{M}\right)$ & $15.3 \pm 4.3$ & $22.3 \pm 4.1^{\prime \prime}$ & $7.1 \pm 0.6^{\prime \prime}$ & $67 \pm 6^{\prime \prime}$ \\
\hline & Meclofenamate $\left(10^{-4} \mathrm{M}\right)$ & $12.2 \pm 2.7$ & $17.0 \pm 2.8^{\prime \prime}$ & $4.8 \pm 1.7^{\prime \prime}$ & $79 \pm 4^{\prime \prime}$ \\
\hline & Metiamide $\left(10^{-4} \mathrm{M}\right)$ & $14.5 \pm 4.3$ & $30.3 \pm 5.9$ & $16.4 \pm 3.2$ & $28 \pm 13$ \\
\hline & Methysergide $\left(10^{-4} \mathrm{M}\right)$ & $17.1 \pm 3.9$ & $33.8 \pm 3.3$ & $16.7 \pm 1.3$ & $21 \pm 13$ \\
\hline \multirow[t]{4}{*}{ B } & Histamine $\left(10^{-4} \mathrm{M}\right)$ & $159.9 \pm 14.7$ & & & \\
\hline & Histamine + metiamide & $20.7 \pm 3.3$ & & & \\
\hline & Histamine + ibuprofen & $177.6 \pm 7.5$ & & & \\
\hline & Histamine + meclofenamate & $163.0 \pm 9.0$ & & & \\
\hline \multirow[t]{3}{*}{$\mathrm{C}$} & Prostaglandin $E_{2} 3 \times 10^{-5} \mathrm{M}$ & $55.7 \pm 8.0$ & & & \\
\hline & Prostaglandin $\mathrm{E}_{2}+$ ibuprofen & - & $58.5 \pm 9.7$ & & \\
\hline & Prostaglandin $\mathrm{E}_{2}+$ meclofenamate & - & $51.7 \pm 2.9$ & & \\
\hline
\end{tabular}

\begin{abstract}
* Incubation conditions as described in detail under methods. All incubations were carried out in presence of a phosphodiesterase inhibitor MIX $\left(5 \times 10^{-4} \mathrm{M}\right)$. All values shown are mean \pm SEM of three separate experiments carried out in triplicate. $\ddagger$ Final concentrations of xanthine and xanthine oxidase were $0.1 \mathrm{mM}$ and $0.025 \mathrm{U} / \mathrm{ml}$, respectively. § Ibuprofen, meclofenamate, metiamide, and methysergide were included in the incubation mixture during the preincubation period. " $P<0.05$ or greater level of significance. I Percentage of inhibition equals (experimental values - control value)/(control value) $\times 100$, where experimental value is the response (basal value subtracted) in the presence of ibuprofen, meclofenamate, metiamide, or methysergide, and control value is the response in their absence.
\end{abstract}

sponse by allopurinol, which is a specific inhibitor of xanthine oxidase, indicate that the observed effect was due to xanthine oxidase acting on its substrate, xanthine, rather than due to contaiminating proteases. Our data also show that the increase in the cyclic AMP content was due to reactive oxygen metabolites rather than to some other products (e.g. uric acid) of the xanthinexanthine oxidase reaction-no effect on cyclic AMP content of glomeruli was noted when uric acid was substituted for xanthinexanthine oxidase in the incubations (data not shown); a significant increase in cyclic AMP $(122 \pm 7 \%, n=4)$ was observed when another substrate (acetaldehyde) for xanthine oxidase was used; and catalase, which destroys hydrogen peroxide, caused marked inhibition of the response to xanthine-xanthine oxidase.

The marked inhibition of the response by catalase and the lack of effect of superoxide dismutase (in a concentration that completely scavenged superoxide) suggested that hydrogen peroxide was the responsible oxygen metabolite for the observed effect. Glucose-glucose oxidase, a system that directly generates hydrogen peroxide without superoxide as an intermediate (31), and direct addition of hydrogen peroxide caused a dose-dependent increase in cyclic AMP content in glomeruli, which provides further evidence for the role of hydrogen peroxide in the observed effect.

In the present study, we did not examine in detail the mechanisms by which hydrogen peroxide increases the cyclic AMP content. However, hydrogen peroxide has been shown to release histamine $(35,36)$ and to enhance PG synthesis (19). Both these local hormones are produced in the glomeruli $(4,5)$, and both have been shown to increase cyclic AMP content in glomeruli $(2,8,37)$. In addition, kidney has been shown to synthesize serotonin (6) and serotonin has been shown to cause a marked increase in the cyclic AMP content in glomeruli (7). As an initial approach, we therefore utilized PG synthesis inhibitors, histamine antagonist, and serotonin antagonist to examine the mechanisms by which reactive oxygen metabolites increase cyclic AMP content in glomeruli (Table V). Our results suggest that reactive oxygen metabolites increase cyclic AMP content in glomeruli by enhancing PG synthesis.

In attempting to relate the significance of our observations to in vivo situations, two obvious questions follow. What would be the source of reactive oxygen metabolites in vivo that could alter glomerular cyclic AMP? And, what is the potential significance of the increase in cyclic AMP? It is now well established that in response to a variety of soluble and particulate stimuli, including immunoglobins, immune complexes, and complement components $(18,38)$, neutrophils and macrophages produce several reactive oxygen metabolites (12). Evidence that neutrophils (39) and monocytes (40) play an important role in proliferative glomerulonephritis suggests that leukocytes activated by complement components or immune complexes may be a potential source of reactive oxygen metabolites in these glomerulonephritides. Baud et al. (19) have estimated that, in vivo, 
infiltrating leukocytes may generate sufficient amounts of hydrogen peroxide to affect glomerular PG synthesis. In addition, in a recent preliminary report (41), it was shown that phorbol myristate acetate injected in the renal artery caused proteinuria that was neutrophil dependent and was prevented by catalase. This observation suggests that leukocytes may generate sufficient reactive oxygen metabolites in vivo to exert their effect on glomeruli. In two other reports $(42,43)$ it was shown that superoxide dismutase was protective in proliferative glomerulonephritis, which again suggests that reactive oxygen metabolites may be generated in sufficient amounts in vivo to have an effect on glomeruli. In a previous study, we demonstrated that isolated glomeruli produce reactive oxygen metabolites in response to plasma membrane perturbation (44). Thus, reactive oxygen metabolites produced by either infiltrating leukocytes and/or glomeruli may alter the level of cyclic AMP in the glomeruli. Extensive experimental evidence from other systems that cyclic AMP modulates inflammatory and immune responses $(1,2,9$, 10) suggests a similar role in glomerular disease. In the glomeruli, the increase in cyclic AMP may potentially exert a beneficial effect by, for example, inhibiting generation of reactive oxygen metabolites $(45,46,47)$ or by inhibiting lysosomal enzyme release (10). On the other hand, potentially detrimental effects include enhanced vascular permeability $(48,49)$ and a reduction in the glomerular ultrafiltration coefficient (3) (which is probably secondary to stimulation of angiotensin formation). Further studies are needed to understand the role of reactive oxygen metabolites and cyclic AMP in glomerular disease.

\section{Acknowledgments}

I thank Julia Lavigne and M. Jeanne Jones for their secretarial assistance. This research was supported by the Medical Research Service of the Veterans Administration Hospital, New Orleans, LA, and by the National Institute of Arthritis, Metabolism, and Digestive Diseases (IR23AM2845-01).

\section{References}

1. Dousa, T. P. 1979. Cyclic nucleotides in renal pathophysiology. In Contemporary Issues in Nephrology. IV. B. M. Brenner and J. H. Stein, editors. Churchill Livingstone Inc., New York. 251-285.

2. Dousa, T. P., S. V. Shah, and H. E. Abboud. 1980. Potential role of cyclic nucleotides in glomerular pathophysiology. In Advances in Cyclic Nucleotide Research. XII. P. Hamet and H. Sands, editors. Raven Press, New York. 285-298.

3. Dworkin, L. D., I. Ichikawa, and B. M. Brenner. 1983. Hormonal modulation of glomerular function. Am. J. Physiol. 244:F95-F104.

4. Abboud, H. E., S. L. Ou, J. A. Velosa, S. V. Shah, and T. P. Dousa. 1982. Dynamics of renal histamine in normal rat kidney and in nephrosis induced by aminonucleoside of puromycin. J. Clin. Invest. 69:327-336.

5. Hassid, A., M. Konieczkowski, and M. J. Dunn. 1979. Prostaglandin synthesis in isolated rat kidney glomeruli. Proc. Natl. Acad. Sci. USA. 76:1155-1159.

6. Stier, C. T., N. Flanagan, D. Manwaring, and H. D. Itskovitz. 1983. Formation of serotonin by rat kidneys in vivo. Kidney Int. 25:317. (Abstr.)
7. Shah, S. V., T. E. Northrup, Y. S. F. Hui, and T. P. Dousa. 1979. Action of serotonin (5-hydroxytryptamine) on cyclic nucleotides in glomeruli of rat renal cortex. Kidney Int. 15:463-472.

8. Abboud, H. E., S. V. Shah, and T. P. Dousa. 1979. Effects of biogenic amines and prostaglandins on CAMP and cGMP in isolated glomeruli. Clin. Res. 27:406. (Abstr.)

9. Lichtenstein, L. M. 1976. Hormone receptor modulation of cAMP in the control of allergic and inflammatory responses. In The Role of Immunological Factors in Infections, Allergic, and Antiimmune Processes. R. F. Beers, Jr., and E. G. Bassett, editors. Raven Press, New York. 339-354.

10. Ignarro, L. J. 1975. Hormonal control of lysosomal enzyme release from human neutrophils by cyclic nucleotides and autonomic neurohormones. In Cyclic Nucleotides in Diseases. B. Weiss, editor. University Park Press, Baltimore. 187-210.

11. Michelakis, A. M., J. Caudle, and G. W. Liddle. 1969. In vitro stimulation of renin production by epinephrine, norepinephrine and cyclic AMP. Proc. Soc. Exp. Biol. Med. 130:748-753.

12. Klebanoff, S. J. 1980. Oxygen metabolism and the toxic properties of phagocytes. Ann. Intern. Med. 93:480-489.

13. Fridovich, I. 1978. The biology of oxygen radicals. Science (Wash. DC). 201:875-880.

14. Fantone, J. C., and P. A. Ward. 1982. Role of oxygen-derived free radicals and metabolites in leukocyte-dependent inflammatory reactions. Am. J. Pathol. 107:397-418.

15. McCord, J. M., K. Wong, S. H. Stokes, W. F. Petrone, and D. English. 1980. Superoxide and inflammation: a mechanism for the antiinflammatory activity of superoxide dismutase. Acta Physiol. Scand. Suppl. 492:25-30.

16. Del Maestro, R. F., H. H. Thaw, J. Bjork, M. Planker, and K. E. Arfors. 1980. Free radicals as mediators of tissue injury. Acta Physiol. Scand. Suppl. 492:43-57.

17. Nathan, C. F., L. H. Brukner, S. C. Silverstein, and Z. A. Cohn. 1979. Extracellular cytolysis by activated macrophages and granulocytes. II. Hydrogen peroxide as a mediator of cytotoxicity. J. Exp. Med. 149:100-113.

18. Sacks, T., C. F. Moldow, P. R. Craddock, T. K. Bowers, and H. S. Jacob. 1978. Oxygen radicals mediate endothelial cell damage by complement-stimulated granulocytes. J. Clin. Invest. 61:1161-1167.

19. Baud, L., M. P. Nivez, D. Chansel, and R. Ardaillou. 1981. Stimulation by oxygen radicals of prostaglandin production by rat renal glomeruli. Kidney Int. 20:332-339.

20. Fong, K. L., P. B. McCay, and J. L. Poyer. 1973. Evidence that peroxidation of lysosomal membranes is initiated by hydroxyl free radicals produced during flavin enzyme activity. J. Biol. Chem. 248:7792-7797.

21. Handin, R. I., R. Karabin, and G. J. Boxer. 1977. Enhancement of platelet function by superoxide anion. J. Clin. Invest. 59:959-965.

22. Lowry, O. H., N. J. Rosenbrough, A. L. Farr, and R. J. Randall. 1951. Protein measurement with the folin phenol reagent. J. Biol. Chem. 193:265-275.

23. Brooker, G., J. F. Harper, W. L. Terasaki, and R. D. Moylan. 1979. Radioimmunoassay of cyclic AMP and cyclic GMP. In Advances in Cyclic Nucleotide Research. Vol. X. G. Brooker, P. Greengard, and G. A. Robison, editors. Raven Press, New York. 10:1-33.

24. McCord, J. M., and I. Fridovich. 1969. Superoxide dismutase: an enzymic function for Erythrocuprein (hemocuprein). J. Biol. Chem. 244:6049-6055.

25. Kalckar, H. M. 1946. Differential spectrophotometry of purine compounds by means of specific enzymes. J. Biol. Chem. 167:429-443.

26. Bergmeyer, H. U., K. Gawehn, and M. Grassl. 1974. In Methods 
of Enzymatic Analysis. H. U. Bergmeyer, editor. Academic Press, Inc. New York. Vol. I. 457-458.

27. Beauchamp, C., and I. Fridovich. 1970. A mechanism for the production of ethylene from methional: the generation of hydroxyl radicals by xanthine oxidase. J. Biol. Chem. 245:4641-4646.

28. Shneyour, A., P. Yehuda, and N. Trainin. 1976. Trypsin-induced increase in intracellular cyclic AMP of lymphocytes. J. Immunol. 117:2143-2149.

29. Richert, N. D., and R. J. Ryan. 1977. Proteolytic enzyme activation of rat ovarian adenylate cyclase. Proc. Natl. Acad. Sci. USA. 74:4857-4861.

30. Elion, G. B., A. Kovensky, and G. H. Hitchings. 1966. Metabolic studies of allopurinol, an inhibitor of xanthine oxidase. Biochem. Pharmacol. 15:863-880.

31. Nilsson, R., F. M. Pick, and R. C. Bray. 1969. EPR studies on reduction of oxygen to superoxide by some biochemical systems. Biochim. Biophys. Acta. 192:145-148.

32. Parks, W. M., J. C. Hoak, and R. L. Czervionke. 1981. Comparative effect of ibuprofen on endothelial and platelet prostaglandin synthesis. J. Pharmacol. Exp. Ther. 219:415-419.

33. White, A. A., K. M. Crawford, C. S. Patt, and P. J. Lad. 1976. Activation of soluble guanylate cyclase from rat lung by incubation or by hydrogen peroxide. J. Biol. Chem. 251:7304-7312.

34. Murad, F., C. K. Mittal, W. P. Arnold, S. Katsuki, and H. Kimura. 1978. Guanylate cyclase: activation by azide, nitro compounds, nitric oxide, and hydroxyl radical and inhibition by hemoglobin and myoglobin. In Advances in Cyclic Nucleotide Research. W. J. George and L. J. Ignarro, editors. Raven Press, New York. Vol. 9. 145-158.

35. Henderson, W. R., E. Y. Chi, and S. J. Klebanoff. 1980. Eosinophil peroxidase-induced mast cell secretion. J. Exp. Med. 152:265-279.

36. Ohmori, H., K. Komoriya, A. Azuma, S. Kurozumi, and Y. H. Oto. 1979. Xanthine oxidase-induced histamine release from isolated rat peritoneal mast cells: involvement of hydrogen peroxide. Biochem. Pharmacol. 28:333-334.

37. Schlondorff, D., P. Yoo, and B. E. Alpert. 1978. Stimulation of adenylate cyclase in isolated rat glomeruli by prostaglandins. Am. J. Physiol. 235(5):F458-F464.
38. Goldstein, I. M., D. Roos, H. B. Kaplan, and G. Weissmann. 1975. Complement and immunoglobulins stimulate superoxide production by human leukocytes independently of phagocytosis. J. Clin. Invest. 56:1155-1163.

39. Cochrane, C. G., E. R. Unanue, and F. J. Dixon. 1965. A role of polymorphonuclear leukocytes and complement in nephrotoxic nephritis. J. Exp. Med. 122:99-116.

40. Holdsworth, S. R., T. J. Neale, and C. B. Wilson. 1981. Abrogation of macrophage-dependent injury in experimental glomerulonephritis in the rabbit. Use of antimacrophage serum. J. Clin. Invest. 68:686-698.

41. Rehan, A., K. J. Johnson, and R. C. Wiggins. 1983. Oxygen free radicals induced proteinuria in rats caused by injection of phorbol myristate acetate (PMA) into the renal artery. Clin. Res. 31:751A. (Abstr.)

42. Stokes, S. H., and J. M. McCord. 1979. Prevention of immunecomplex induced glomerulonephritis by superoxide dismutase. Ala. $J$. Med. Sci. 16(1):33. (Abstr.)

43. Jennette, J. C., C. P. Hyson, and S. S. Iskandar. 1982. Palliative effect of superoxide dismutase on heterologous protein induced glomerulonephritis. Fed. Proc. No. 331. 41:325A. (Abstr.)

44. Shah, S. V. 1981. Light emission by isolated rat glomeruli in response to phorbol myristate acetate. J. Lab. Clin. Med. 98:46-57.

45. Smith, R. L., N. H. Hunt, J. E. Merrit, T. Evans, and M. J. Weidemann. 1980. Cyclic nucleotide metabolism and reactive oxygen production by macrophages. Biochem. Biophys. Res. Commun. 96:1079_ 1087.

46. Simochowitz, L., L. C. Fischbein, I. Spilberg, and J. P. Atkinson. 1980. Induction of a transient elevation in intracellular levels of adenosine- 3 '-5' cyclic monophosphate by chemotactic factors: an early event in human neutrophil activation. J. Immunol. 124:1482-1491.

47. Sedor, J. R., and H. E. Abboud. 1984. Histamine modulates superoxide anion production in cultured rat mesangial cells. 1. Kidney Int. 25(1):218. (Abstr.)

48. Kahn, A., and E. Brachet. 1978. The role of various prostaglandins on the correlation between permeability to albumin and cAMP levels in the isolated mesentery. Prostaglandins. 16:939-944.

49. Kahn, A., and E. Brachet. 1979. The permeability coefficient of albumin of the isolated rat mesentery. Biochim. Biophys. Acta 588:219231. 